\title{
Epistatic interaction between $\alpha$ - and $\gamma$-adducin influences peripheral and central pulse pressures in white Europeans
}

\author{
Marcin Cwynar ${ }^{\mathrm{a}}$, Jan A. Staessen ${ }^{\mathrm{b}}$, Milena Tichác ${ }^{\mathrm{C}}$, Tim Nawrot ${ }^{\mathrm{b}}$, \\ Lorena Citterio ${ }^{d}$, Tatiana Kuznetsova ${ }^{b}$, Wiktoria Wojciechowska ${ }^{\mathrm{e}}$, Katarzyna \\ Stolarz $^{\mathrm{e}}$, Jan Filipovskýc ${ }^{\mathrm{c}}$, Kalina Kawecka-Jaszcz ${ }^{\mathrm{e}}$, Tomasz Grodzicki ${ }^{\mathrm{a}}$, \\ Harry A. Struijker-Boudier ${ }^{f}$, Lutgarde Thijs ${ }^{b}$, Luc M. Van Bortel ${ }^{g}$ and Giuseppe \\ Bianchid ${ }^{\mathrm{d}}$ on behalf of the European Project On Genes in Hypertension \\ (EPOGH) Investigators
}

Background Adducin is a membrane skeleton protein consisting of $\alpha$ - and $\beta$ - or $\alpha$ - and $\gamma$-subunits. Mutations in $\alpha$ - and $\beta$-adducin are associated with hypertension. In the European Project on Genes in Hypertension, we investigated whether polymorphisms in the genes encoding $\alpha$-adducin (Gly460Trp), $\beta$-adducin (C1797T) and $\gamma$-adducin (A386G), alone or in combination, affected pulse pressure (PP), an index of vascular stiffness.

Methods We measured peripheral and central PP by conventional sphygmomanometry and applanation tonometry, respectively. We randomly recruited 642 subjects (162 nuclear families and 70 unrelated individuals) from three European populations. In multivariate analyses, we used generalized estimating equations and the quantitative transmission disequilibrium test.

Results Peripheral and central PP averaged 46.1 and $32.6 \mathrm{mmHg}$, respectively. Among carriers of the $\alpha$-adducin Trp allele, peripheral and central PP were 5.8 and 4.7 $\mathrm{mmHg}$ higher in $\gamma$-adducin GG homozygotes than in their AA counterparts, due to an increase in systolic pressure. $\gamma$-Adducin GG homozygosity was associated with lower urinary $\mathrm{Na}^{+} / \mathrm{K}^{+}$ratio among $\alpha$-adducin Trp allele carriers and with higher urinary aldosterone excretion among $\alpha$-adducin GlyGly homozygotes. Sensitivity analyses in founders and offspring separately, and tests based on the transmission of the $\gamma$-adducin $\mathrm{G}$ allele across families, confirmed the interaction between the $\alpha$ - and $\gamma$-adducin genes.

Conclusions In $\alpha$-adducin Trp allele carriers, peripheral and central PP increased with the $\gamma$-adducin G allele. This epistatic interaction is physiologically consistent with the heterodimeric structure of the protein and its influence

\section{Introduction}

Adducin is an ubiquitously expressed membraneskeleton protein, which consists of either $\alpha$ - and $\beta$ - or $\alpha$ - and $\gamma$-subunits, which to a large extent are similar in amino acid sequence and domain organization [1]. Point mutations of the $\alpha$ - and $\beta$-adducin subunits account for up to $50 \%$ of the blood pressure difference between on transmembranous sodium transport. $J$ Hypertens 23:961-969 (c) 2005 Lippincott Williams \& Wilkins.

Journal of Hypertension 2005, 23:961-969

Keywords: adducin, epistatic interaction, genetic polymorphism, large arteries, pulse pressure, sodium

aDepartment of Internal Medicine and Gerontology, Medical College, Jagiellonian University, Cracow, Poland, 'b Study Coordinating Centre, Hypertension and Cardiovascular Rehabilitation Unit, Department of Molecular and Cardiovascular Research, University of Leuven, Leuven, Belgium, 'Department of Internal Medicine II, Charles University Medical School, Pilsen, Czech Republic,

${ }^{d}$ Cattedra e Scuola di Nefrologia, Universitá Vita e Salute San Raffaele, Milano, Italy, ${ }^{e}$ First Cardiac Department, Medical College, Jagiellonian University, Cracow, Poland, 'Department of Pharmacology and Toxicology, Cardiovascular Research Institute, University of Maastricht, Maastricht, The Netherlands and ${ }^{9}$ Division of Clinical Pharmacology and Pharmacotherapy, Heymans Institute of Pharmacology, University of Ghent, Ghent, Belgium.

Sponsorship: Nuclear families were recruited in the framework of the European Project on Genes in Hypertension, which was supported by the European Union (contract numbers IC15-CT98-0329-EPOGH and QLGI-CT-2000-01137EURNETGEN) and which is endorsed by the European Council for

Cardiovascular Research and the European Society of Hypertension. The studies in Belgium and Poland were also supported by research grants G.0291.98 and G.0424.03 from the Fonds voor Wetenschappelijk Onderzoek Vlaanderen (Brussels, Belgium), a special research grant (OT/99/28) from the Katholieke Universiteit Leuven (Leuven, Belgium) and the International Scientific and Technological Cooperation between Poland and Flanders (contract number BIL 00/18). The Czech Ministry of Education (Prague, Czech Republic) and the Ministero Universitá e Ricerca Scientifica (Rome, Italy) provided additional funding to J.F. (OK 375 and OK 376) and G.B. (FIRB RBNE01724C-001 and PRIN 200206779-001), respectively.

Correspondence and requests for reprints to Jan A. Staessen MD PhD, Study Coordinating Centre, Laboratory of Hypertension, Hypertension and

Cardiovascular Rehabilitation Unit, Department of Molecular and Cardiovascular Research, Campus Gasthuisberg, University of Leuven, Herestraat 49, B-3000 Leuven, Belgium.

Tel: +32 16347104; fax: +3216347106;

e-mail: jan.staessen@med.kuleuven.ac.be

Received 12 July 2004 Revised 28 January 2005 Accepted 28 January 2005

See editorial commentary page 929

Milan normotensive (MNS) and hypertensive (MHS) rats [2]. Enhanced $\mathrm{Na}^{+}, \mathrm{K}^{+}$-ATPase activity [3,4] and increased renal tubular sodium reabsorption [5] explain the rise in blood pressure in MHS rats.

In previous studies, we demonstrated that human carriers of the mutated $\alpha$-adducin 460Trp allele are characterized 
by an increased risk of hypertension [6] and slight impairment of renal function [7]. Additional observations in Belgian [8] and other European populations [9] gave rise to the hypothesis that the $\beta$-adducin C1797T polymorphism might also be associated with hypertension, especially in post-menopausal women. Furthermore, the Gly460Trp polymorphism in the $\alpha$-adducin gene seems to confer a genetic background favouring thickening of the intima-media of the femoral artery [10] and influencing the distensibility of the large arteries [11].

Pulse pressure is an age-related index reflecting vascular stiffness, the amplitude and velocity of reflected waves and cardiac stroke volume [12]. In view of the evidence outlined above [6-11], we investigated, in randomly recruited participants of the European Project on Genes in Hypertension (EPOGH), whether genetic variation in the three adducin subunits, alone or in combination, impacted on peripheral and central pulse pressures. Our analysis accounted for salt intake, estimated from the urinary excretion of sodium, and for other host and environmental determinants of cardiovascular function. In the context of this paper, epistasis refers to nonadditive gene-gene interactions.

\section{Methods \\ Study population}

The European Project on Genes in Hypertension (EPOGH) was conducted according to the principles outlined in the Helsinki Declaration for investigation of human subjects [13]. The Ethics Committee of each institution approved the protocol. Participants gave informed written consent.

Three EPOGH centres opted to take part in vascular phenotyping. They randomly recruited nuclear families of Caucasian extraction, including offspring with a minimum age of 10 years in Belgium and 18 years in the two other countries. Overall, the response rate was $82 \%$. Of 870 participants recruited in Cracow (Poland, $n=302$ ), Hechtel-Eksel (Belgium, $n=380$ ) and Pilsen (Czech Republic, $n=188$ ), we discarded 17 from analysis because the recorded pulse wave was of insufficient quality, and 26 because of missing genotypes. In addition, we detected nine cases of inconsistency in Mendelian segregation. The Belgian sample included seven extended families spanning more than two generations. Because there is no generally agreed algorithm to construct the variance-covariance matrix for correlated data within extended pedigrees using generalized estimating equations (see below), we selected from each complex family the most informative nuclear unit with the largest number of phenotypes and genotypes. This procedure removed 176 Belgian subjects from our analyses. Thus, the overall number of participants analysed statistically totalled 642 .

\section{Phenotypes and genotypes}

After subjects had rested for $15 \mathrm{~min}$, four observers (one in Belgium, one in the Czech Republic and two in Poland), recorded the radial arterial waveform at the dominant arm by applanation tonometry for $8 \mathrm{~s}$. We used a high-fidelity SPC-301 micromanometer (Millar Instruments, Inc., Houston, Texas, USA) interfaced with a laptop computer running the SphygmoCor software, version 6.31 (AtCor Medical Pty Ltd, West Ryde, New South Wales, Australia). We discarded recordings when the systolic or diastolic variability of consecutive waveforms exceeded $5 \%$, or when the amplitude of the pulse wave signal was less than $80 \mathrm{mV}$. We calibrated the pulse wave by measuring blood pressure in the contralateral arm immediately before the recordings. From the radial signal, the SphygmoCor software calculates the aortic pulse wave by means of a population-based and validated transfer function [14]. For statistical analysis, we used the average of the central waveforms over the 8-s measurement period. The blood pressure phenotype was the average of five consecutive readings obtained at one home visit. Peripheral and central pulse pressures were defined as the differences between systolic and diastolic blood pressure, derived from the brachial blood pressure measured at the subjects' homes and from the aortic pulse wave, respectively. From the home readings, we calculated mean arterial pressure as diastolic pressure plus one-third of pulse pressure. We defined hypertension as a blood pressure of at least $140 \mathrm{mmHg}$ systolic or $90 \mathrm{mmHg}$ diastolic, or as the use of antihypertensive drugs. The observers involved in phenotyping were unaware of the subjects' genotype.

We administered a standardized questionnaire to obtain information on each subject's medical history, smoking and drinking habits and use of medications. The participants collected a $24-\mathrm{h}$ urine sample in a wide-neck plastic container, for the measurement of sodium, potassium, creatinine and aldosterone. The participants did not receive any prior advice with regard to their salt intake. One 24-h urine collection might be insufficient to characterize an individual's habitual sodium intake, but it does accurately reflect the average salt consumption of groups of subjects [15]. For statistical analysis of the urinary phenotypes, we excluded 23 subjects because, according to published criteria [16], their urine samples were under- or overcollected or because they were on antihypertensive treatment $(n=123)$.

Blood was sampled in ACD buffer and stored at $-80^{\circ} \mathrm{C}$. DNA was extracted according to standard methods. Genotyping was carried out on an ABI Prism 7700 Sequence Detection System (Applied Biosystems Inc., Foster City, California, USA) using a $5^{\prime}$ nuclease detection assay. Primers and probes for the $\alpha$-adducin Gly460Trp (rs4961 dbSNP) and the $\beta$-adducin 
C1797T (rs4984 dbSNP) polymorphisms have been described previously [6,9].

For $\gamma$-adducin (rs3731566 dbSNP), the forward and reverse primers were 5'-TGGAGGTGGGAATTGAAGAGA- $3^{\prime}$ and $5^{\prime}$-CCGGAATCTGAATTGAAAAACAA- $3^{\prime}$, respectively. The $A$ and $G$ probes were $5^{\prime} \mathrm{FAM}-\mathrm{TG}$ TCA-

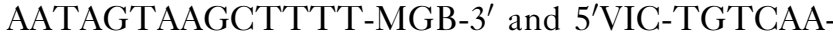
GTAGTAAGCTTT-MGB-3'. Each $25 \mu$ of polymerase chain reaction (PCR) fluid contained: $50 \mathrm{ng}$ genomic DNA, $1200 \mathrm{nmol} / \mathrm{l}$ primers, $400 \mathrm{nmol} / \mathrm{l} \mathrm{FAM}$-probe and $120 \mathrm{nmol} / \mathrm{l}$ VIC-probe. The amplification conditions were: $50^{\circ} \mathrm{C}$ for $2 \mathrm{~min}$; $95^{\circ} \mathrm{C}$ for $10 \mathrm{~min}$; followed by 42 cycles at $92^{\circ} \mathrm{C}$ for $15 \mathrm{~s}$ and at $60^{\circ} \mathrm{C}$ for $1 \mathrm{~min}$.

\section{Statistical methods}

Database management and most statistical analyses were performed with SAS software version 8.1 (SAS Institute Inc., Cary, North Carolina, USA). Population means and proportions were compared by Tukey's multiple means test and the $\chi^{2}$ statistic with Bonferroni's adjustment for multiple comparisons, respectively. If Shapiro-Wilk's statistic showed significant departure from normality, we analysed logarithmically transformed variables. We searched for possible covariates of the pulse pressures, using stepwise multiple regression with the $P$ value for independent variables to enter and to stay in the model set at 0.10

In a population-based approach, we tested the association of continuous traits with the genotypes of interest by use of generalized estimating equations (GEE). This approach allows adjustment for covariates as well as for the non-independence of observations within families [17]. In GEE, we also tested for heterogeneity across populations, using appropriate interaction terms with the genotypes. Furthermore, in family-based analyses, we performed a transmission disequilibrium test for quantitative traits (QTDT). We evaluated the within- and between-family components of phenotypic variance, using the orthogonal model as implemented by Abecasis et al. [18] in the QTDT software, version 2.3 (http://www/ sph.umich.edu/cgs/abecasis/QTDT/download).

\section{Results}

\section{Characteristics of the participants}

Table 1 gives the characteristics of participants by country. Overall, the study population included 572 subjects from 162 nuclear families and 70 unrelated individuals. Mean $( \pm \mathrm{SD})$ age of the 303 founders and 339 offspring was $51.8 \pm 8.6$ years and $30.0 \pm 10.7$ years, respectively. The number of sibs per nuclear family amounted to 1 in 30 families, 2 in 110 families, and ranged from 3 to 8 in 22 families. The Belgian participants were older than the Slavic subjects. Compared to Polish subjects, fewer Belgians were on antihypertensive drug treatment. Czechs more frequently reported regular alcohol intake ( $\geq 5 \mathrm{~g} /$ day $)$ than Belgians and Polish subjects. Urinary sodium excretion was on average $48 \mathrm{mmol} /$ day and $32 \mathrm{mmol} /$ day higher in Poland than in Belgium and the Czech Republic, respectively. The urinary aldosterone excretion was lowest in Poland. Figure 1 shows the sex- and

Table 1 Characteristics of the study participants by country

\begin{tabular}{|c|c|c|c|}
\hline & Belgium & Czech Republic & Poland \\
\hline Number & 194 & 162 & 286 \\
\hline \multicolumn{4}{|l|}{ Anthropometric characteristics } \\
\hline Age (years) & $46.7 \pm 14.6$ & $38.0 \pm 13.5^{x}$ & $37.3 \pm 13.9^{x}$ \\
\hline Female gender $(\%)$ & 56.7 & 54.3 & 53.9 \\
\hline Body mass index $\left(\mathrm{kg} / \mathrm{m}^{2}\right)$ & $25.8 \pm 4.1$ & $26.2 \pm 4.7$ & $25.4 \pm 4.9$ \\
\hline \multicolumn{4}{|l|}{ Haemodynamic measurements } \\
\hline Peripheral pulse pressure $(\mathrm{mmHg})^{\mathrm{a}}$ & $46.7 \pm 10.7$ & $45.0 \pm 10.3$ & $46.4 \pm 9.4$ \\
\hline Central pulse pressure $(\mathrm{mmHg})$ & $34.4 \pm 9.3$ & $29.3 \pm 9.1^{x}$ & $33.4 \pm 10.7^{y}$ \\
\hline Systolic pressure $(\mathrm{mmHg})^{\mathrm{a}}$ & $123.4 \pm 15.2$ & $122.5 \pm 15.8$ & $125.7 \pm 15.3$ \\
\hline Diastolic pressure $(\mathrm{mmHg})^{\mathrm{a}}$ & $76.7 \pm 10.9$ & $77.5 \pm 10.4$ & $79.3 \pm 10.4^{x}$ \\
\hline Pulse rate (beats/min) & $62.7 \pm 9.4$ & $67.1 \pm 9.8^{x}$ & $73.4 \pm 11.4^{x, y}$ \\
\hline \multicolumn{4}{|l|}{ Questionnaire data } \\
\hline Hypertensives $(\%)^{\mathrm{b}}$ & 29.4 & 29.0 & $39.9^{x, y}$ \\
\hline Antihypertensive treatment $(\%)$ & 13.4 & 20.4 & $22.7^{x}$ \\
\hline Current smokers (\%) & 29.4 & 25.3 & 27.3 \\
\hline Alcohol intake $\geq 5 \mathrm{~g} /$ day (\%) & 28.4 & $43.2^{x}$ & $18.9^{y}$ \\
\hline \multicolumn{4}{|l|}{ Urinary measurements $^{\mathrm{c}}$} \\
\hline Volume (I/day) & $1.59 \pm 0.74$ & $1.92 \pm 0.74^{x}$ & $1.47 \pm 0.55^{y}$ \\
\hline Sodium (mmol/day) & $197 \pm 66$ & $213 \pm 89$ & $245 \pm 89^{x, y}$ \\
\hline Potassium (mmol/day) & $70 \pm 28$ & $62 \pm 26^{x}$ & $64 \pm 23^{x}$ \\
\hline $\mathrm{Na}^{+} / \mathrm{K}^{+}$ratio (units) & $3.0 \pm 1.0$ & $3.6 \pm 1.4^{x}$ & $4.1 \pm 1.4^{x, y}$ \\
\hline Aldosterone (nmol/day) & $21.0(18.6-23.4)$ & $18.0(16.0-20.0)$ & $10.4(8.4-12.4)^{x, y}$ \\
\hline Creatinine (mmol/day) & $10.8 \pm 3.6$ & $14.0 \pm 4.2^{\mathrm{x}}$ & $12.0 \pm 4.2^{x, y}$ \\
\hline
\end{tabular}

Values are arithmetic means \pm SD, geometric means (95\% confidence interval) or the percentage of subjects. $P$ values for the between-country differences were adjusted for multiple comparisons by Tukey's test (means) or Bonferroni's method (proportions). ${ }^{\mathrm{x}} P \leq 0.05$ versus Belgium; ${ }^{\mathrm{y}} P \leq 0.05$ versus the Czech Republic. ${ }^{\mathrm{a} A v e r a g e ~ o f ~ f i v e ~}$ measurements obtained at one home visit; ${ }^{b}$ We defined hypertension as a blood pressure of at least $140 \mathrm{mmHg}$ systolic or $90 \mathrm{mmHg}$ diastolic or as the use of antihypertensive drugs; ' The number of subjects with a 24-h urine collection was 166 in Belgium, 112 in the Czech Republic and 218 in Poland. 

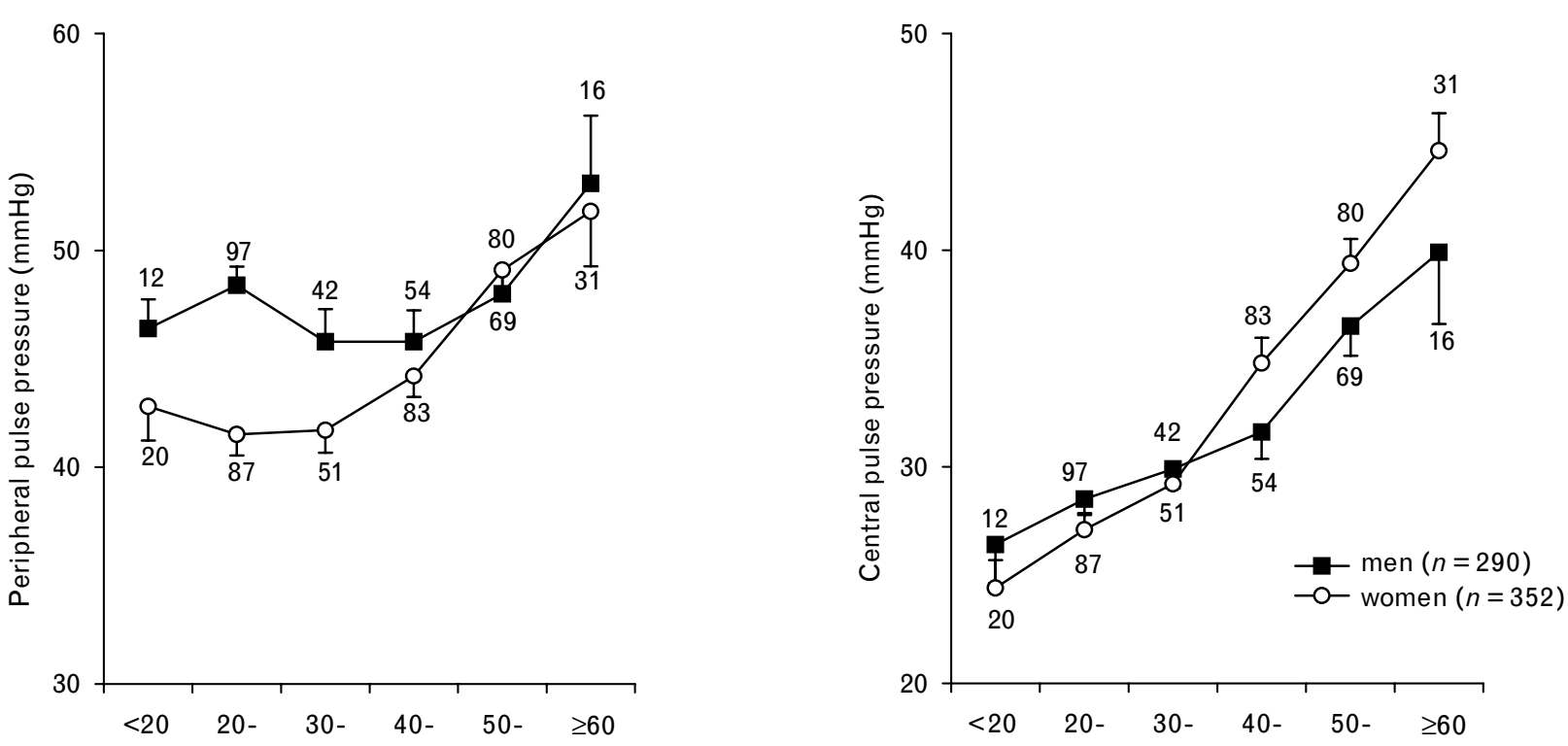

Age class (years)

Peripheral and central pulse pressures by sex and age class. Values are unadjusted means \pm SD. The number of subjects contributing to each mean is given.

age-dependency of the peripheral and central pulse pressures which, in the whole study population, averaged $46.1 \pm 10.1$ and $32.6 \pm 10.1 \mathrm{mmHg}$, respectively.

Stepwise multiple regression demonstrated that peripheral pulse pressure significantly and independently increased with male gender (regression coefficient $[\beta] \pm \mathrm{SE} ; 2.22 \pm 0.84 \mathrm{mmHg} ; P=0.008)$, mean arterial pressure $(0.17 \pm 0.04 \mathrm{mmHg} / \mathrm{mmHg} ; P=0.0001)$ and that it was higher in patients on antihypertensive treatment $(3.25 \pm 1.10 \mathrm{mmHg} ; P=0.003)$. Peripheral pulse pressure also tended to increase with current smoking $(1.54 \pm 0.86 \mathrm{mmHg} ; \quad P=0.08)$ and to decrease with pulse rate $(-0.07 \pm 0.04 \mathrm{mmHg} /$ beat; $P=0.07)$. Central pulse pressure increased with age $(0.25 \pm 0.03 \mathrm{mmHg} /$ year; $P=0.0001)$, mean arterial pressure $(0.23 \pm$
$0.03 \mathrm{mmHg} / \mathrm{mmHg} ; P=0.0001)$ and current smoking $(1.78 \pm 0.71 \mathrm{mmHg} ; P=0.01)$, whereas it decreased with male gender $(-2.20 \pm 0.69 \mathrm{mmHg} ; P=0.002)$, pulse rate $(-0.22 \pm 0.03 \mathrm{mmHg} /$ beat; $P=0.0001)$ and regular alcohol intake $(-2.00 \pm 0.79 \mathrm{mmHg} ; P=0.01)$. We adjusted the population-based and family-based analyses of pulse pressures for all aforementioned covariates as well as for country (peripheral pulse pressure) or observer (central pulse pressure).

In all countries, aldosterone excretion adjusted for sex and age was closely correlated with urinary sodium and potassium. With additional adjustment for country, the overall partial correlation coefficients were -0.11 for sodium, 0.28 for potassium and -0.37 for the $\mathrm{Na}^{+} / \mathrm{K}^{+}$ ratio $(P<0.01$, for all $)$. In the population-based and

Table 2 Genotype and allele frequencies by country ordered according to the prevalence of the major allele

\begin{tabular}{|c|c|c|c|c|c|c|}
\hline \multirow{2}{*}{$\frac{\text { Gene }}{\alpha \text {-Adducin }}$} & \multirow[t]{2}{*}{ Country } & \multicolumn{2}{|c|}{ Allele } & \multicolumn{3}{|c|}{ Genotype } \\
\hline & & Gly & Trp & GlyGly & GlyTrp & TrpTrp \\
\hline & Belgium & 283 (72.9) & $105(27.1)$ & $106(54.6)$ & $71(36.6)$ & $17(8.8)$ \\
\hline & Czech Republic & $258(79.6)$ & $66(20.4)$ & $102(63.0)$ & 54 (33.3) & $6(3.7)$ \\
\hline & Poland & $481(84.1)$ & $91(15.9)$ & $199(69.6)$ & $83(29.0)$ & $4(1.4)$ \\
\hline \multirow[t]{4}{*}{$\beta$-Adducin } & & C & $\mathrm{T}$ & CC & CT & TT \\
\hline & Czech Republic & 271 (83.6) & $53(16.4)$ & $112(69.1)$ & $47(29.0)$ & $3(1.9)$ \\
\hline & Belgium & $347(89.4)$ & $41(10.6)$ & $156(80.4)$ & $35(18.0)$ & $3(1.6)$ \\
\hline & Poland & $514(89.9)$ & $58(10.1)$ & $232(81.1)$ & $50(17.5)$ & $4(1.4)$ \\
\hline \multirow{4}{*}{$\gamma$-Adducin } & & A & G & AA & AG & GG \\
\hline & Czech Republic & $174(53.7)$ & $150(46.3)$ & $50(30.9)$ & $74(45.7)$ & 38 (23.5) \\
\hline & Belgium & $216(55.7)$ & 172 (44.3) & $69(35.6)$ & $78(40.2)$ & $47(24.2)$ \\
\hline & Poland & 322 (56.3) & $250(43.7)$ & $90(31.5)$ & $142(49.7)$ & $54(18.9)$ \\
\hline
\end{tabular}

Values indicate number of alleles or genotypes (\%). Braces join countries with similar allele frequencies. 
Table 3 Peripheral and central pulse pressures by genotypes

\begin{tabular}{|c|c|c|c|c|c|c|}
\hline \multirow{2}{*}{$\begin{array}{l}\text { Polymorphism } \\
\alpha \text {-adducin Gly460Trp }\end{array}$} & \multirow[t]{2}{*}{ Pulse pressures } & \multirow{2}{*}{$\frac{\text { Number }}{\text { GlyGly/GlyTrp }+ \text { TrpTrp }}$} & \multicolumn{3}{|c|}{ Adjusted means \pm SE } & \multirow[t]{2}{*}{$P$} \\
\hline & & & GlyGly & Gly & Trp & \\
\hline & Peripheral & $407 / 235$ & $46.4 \pm 0.5$ & & & $0.40 *$ \\
\hline & Central & $407 / 235$ & $32.3 \pm 0.4$ & & & $0.69 *$ \\
\hline \multirow[t]{3}{*}{$\beta$-adducin C1797T } & & $\mathrm{CC} / \mathrm{CT}+\mathrm{TT}$ & $\mathrm{CC}$ & \multicolumn{2}{|c|}{$\mathrm{CT}+\mathrm{TT}$} & \\
\hline & Peripheral & $500 / 142$ & $45.9 \pm 0.5$ & \multicolumn{2}{|c|}{$47.1 \pm 0.9$} & $0.24^{\dagger}$ \\
\hline & Central & $500 / 142$ & $32.2 \pm 0.4$ & \multicolumn{2}{|c|}{$33.2 \pm 0.7$} & $0.24^{\dagger}$ \\
\hline \multirow[t]{3}{*}{$\gamma$-adducin A386G } & & AA/AG/GG & AA & AG & GG & \\
\hline & Peripheral & 209/294/139 & $45.8 \pm 0.7$ & $46.0 \pm 0.6$ & $47.1 \pm 0.9$ & $0.46^{\ddagger}$ \\
\hline & Central & 209/294/139 & $32.3 \pm 0.5$ & $32.3 \pm 0.4$ & $33.0 \pm 0.6$ & $0.34^{\ddagger}$ \\
\hline
\end{tabular}

Pulse pressures were adjusted for sex, age, pulse rate, mean blood pressure, current smoking, alcohol intake, antihypertensive treatment and country (peripheral pulse pressure) or observer (central pulse pressure). P values were derived by GEE. *, For comparison between GlyGly versus GlyTrp + TrpTrp; ${ }^{\dagger}$, for comparison between CC versus $\mathrm{CT}+\mathrm{TT} ;{ }^{\ddagger}$, for comparison across the $\gamma$-adducin genotypes.

family-based analyses involving urinary phenotypes in untreated subjects $(n=496)$, we adjusted for country, sex, age, body mass index, alcohol intake and, in women, also for the use of oral contraceptives. The adjustment of urinary aldosterone additionally accounted for sodium and potassium excretion.

The within-country frequencies of the genotypes (Table 2) complied with Hardy-Weinberg equilibrium $(0.07 \leq P \leq 0.91)$. The genotype and allele frequencies were similar across countries for the $\gamma$-adducin gene. In Belgium and the Czech Republic, respectively, the $\alpha$-adducin Trp allele and the $\beta$-adducin $\mathrm{T}$ allele were more prevalent than in the other countries.

\section{Population-based association study}

Because across centres there was no heterogeneity in the phenotype-genotype relations $(0.06 \leq P \leq 0.99)$, we combined all countries. Furthermore, for none of the phenotype-genotype associations, did we find significant interactions with gender $(0.28 \leq P \leq 0.96)$, age $(0.36 \leq P \leq 0.99)$ or generation (parents versus offspring; $0.52 \leq P \leq 0.88)$.

In single-gene analyses involving all subjects (Table 3 ), founders $(0.29 \leq P \leq 0.86)$ or offspring $(0.29 \leq P \leq 0.92)$, the GEE approach did not reveal any significant associa- tion between peripheral or central pulse pressure and the three adducin polymorphisms. This was also the case for the urinary excretion of sodium, potassium and aldosterone $(0.06 \leq P \leq 0.98)$. However, multiple-gene analyses demonstrated significant interactions between the $\alpha$ and $\gamma$-adducin genotypes in relation to the peripheral and central pulse pressures, the urinary $\mathrm{Na}^{+} / \mathrm{K}^{+}$ratio and aldosterone excretion (Table 4). Among $\alpha$-adducin GlyGly homozygotes, the aldosterone excretion decreased with the number of $\gamma$-adducin $G$ alleles (Table 4). This trend explained the overall borderline significant interaction between $\alpha$ - and $\gamma$-adducin in relation to urinary aldosterone. Among carriers of the $\alpha$-adducin Trp allele, the peripheral and central pulse pressures were $5.8 \mathrm{mmHg}$ [95\% confidence interval (CI) 2.3-9.3; $P=0.001]$ and $4.7 \mathrm{mmHg}$ (CI 2.0-7.4; $P=0.0002)$ higher in $\gamma$-adducin GG homozygotes than in their AA counterparts. These genetic effects on pulse pressure were due to increases in systolic pressure, averaging $5.0 \mathrm{mmHg}$ (CI 2.9-7.1; $P=0.02$ ) peripherally and $4.9 \mathrm{mmHg}$ (CI 3.3-6.5; $P=0.002)$ centrally. Furthermore, among $\alpha$-adducin Trp carriers, the urinary $\mathrm{Na}^{+} / \mathrm{K}^{+}$ratio was 0.8 units (CI $0.4-1.2 ; P=0.004)$ lower in $\gamma$-adducin GG homozygotes than in A-allele carriers. In $\alpha$-adducin GlyGly homozygotes, the $\gamma$-adducin polymorphism influenced neither peripheral nor central pulse pressures nor the urinary $\mathrm{Na}^{+} / \mathrm{K}^{+}$ratio (Table 4 ).

Table 4 Pulse pressures and urinary phenotypes by $\alpha$ - and $\gamma$-adducin genotypes

\begin{tabular}{|c|c|c|c|c|c|c|c|c|c|c|}
\hline \multirow[b]{3}{*}{$\alpha / \gamma$-Adducin genotypes } & \multirow[b]{3}{*}{ Number } & \multicolumn{4}{|c|}{ Pulse pressures } & \multirow[b]{3}{*}{ Number } & \multicolumn{4}{|c|}{ Urinary phenotypes } \\
\hline & & \multicolumn{2}{|c|}{ Peripheral } & \multicolumn{2}{|c|}{ Central } & & \multicolumn{2}{|c|}{$\mathrm{Na}^{+} / \mathrm{K}^{+}$ratio } & \multicolumn{2}{|c|}{ Aldosterone excretion } \\
\hline & & Mean \pm SE & $P_{\text {int }}$ & Mean \pm SE & $P_{\text {int }}$ & & Mean \pm SE & $P_{\text {int }}$ & Mean $(95 \% \mathrm{Cl})$ & $P_{\text {int }}$ \\
\hline GlyGly/AA & 137 & $46.9 \pm 0.9$ & & $32.8 \pm 0.7$ & & 103 & $3.6 \pm 0.1$ & & $18.1(15.5-20.7)$ & \\
\hline GlyGly/AG & 178 & $46.2 \pm 0.7$ & & $32.4 \pm 0.6$ & & 129 & $3.7 \pm 0.1$ & & $14.1(12.3-16.1)$ & \\
\hline GlyGly/GG & 92 & $45.9 \pm 1.1$ & & $31.5 \pm 0.7$ & & 77 & $3.6 \pm 0.1$ & & $12.5(10.4-14.9)$ & \\
\hline GlyTrp + TrpTrp/AA & 72 & $43.6 \pm 1.1$ & & $31.4 \pm 0.9$ & & 55 & $4.2 \pm 0.2$ & & $14.0(11.7-16.8)$ & \\
\hline GlyTrp + TrpTrp/AG & 116 & $45.7 \pm 0.8$ & & $32.1 \pm 0.7$ & & 92 & $3.4 \pm 0.1$ & & $14.4(12.6-16.5)$ & \\
\hline GlyTrp + TrpTrp/GG & 47 & $49.4 \pm 1.4$ & 0.02 & $36.1 \pm 1.1$ & 0.004 & 40 & $3.4 \pm 0.1$ & 0.004 & $15.2(12.1-19.0)$ & 0.05 \\
\hline
\end{tabular}

Pulse pressures were adjusted as in Table 3. Urinary phenotypes in 496 untreated subjects were adjusted for country, sex, age, body mass index, alcohol intake and, in women, also for the use of oral contraceptives. The adjustment of urinary aldosterone additionally accounted for sodium and potassium excretion. $P_{\text {int }}$ is the probability of the interaction between $\alpha$ - and $\gamma$-adducin. Braces join trios of means which are similar. 
Fig. 2
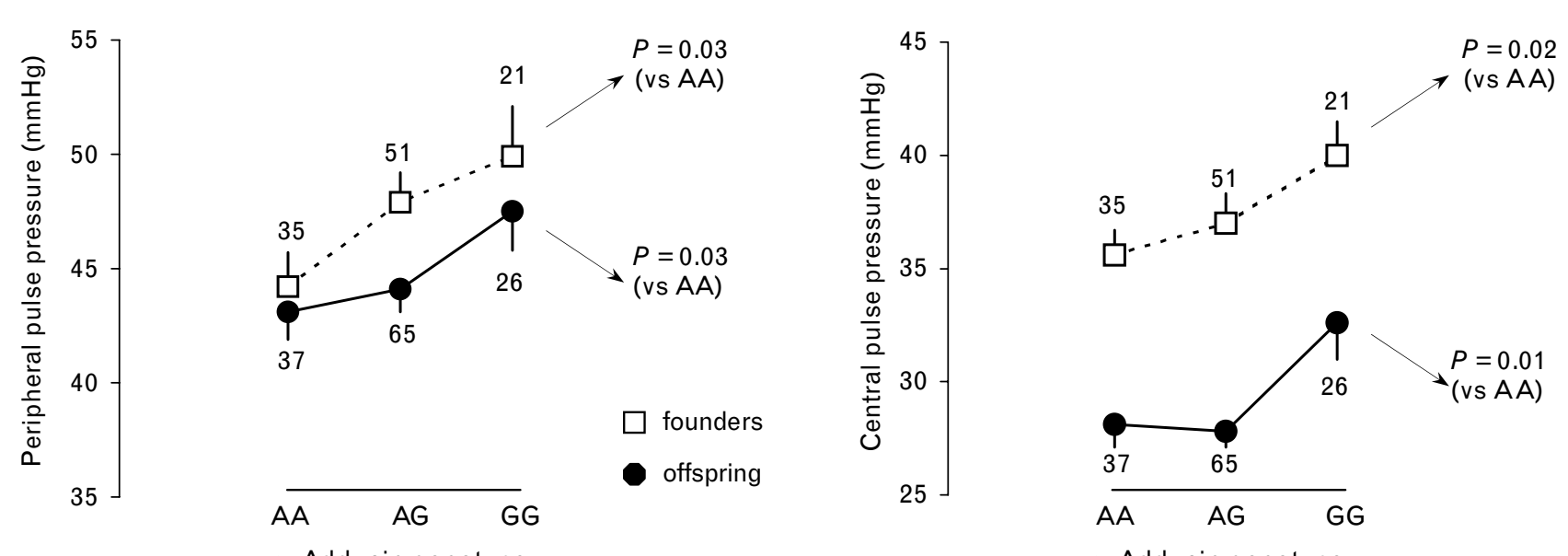

$\gamma$-Adducin genotype

$\gamma$-Adducin genotype
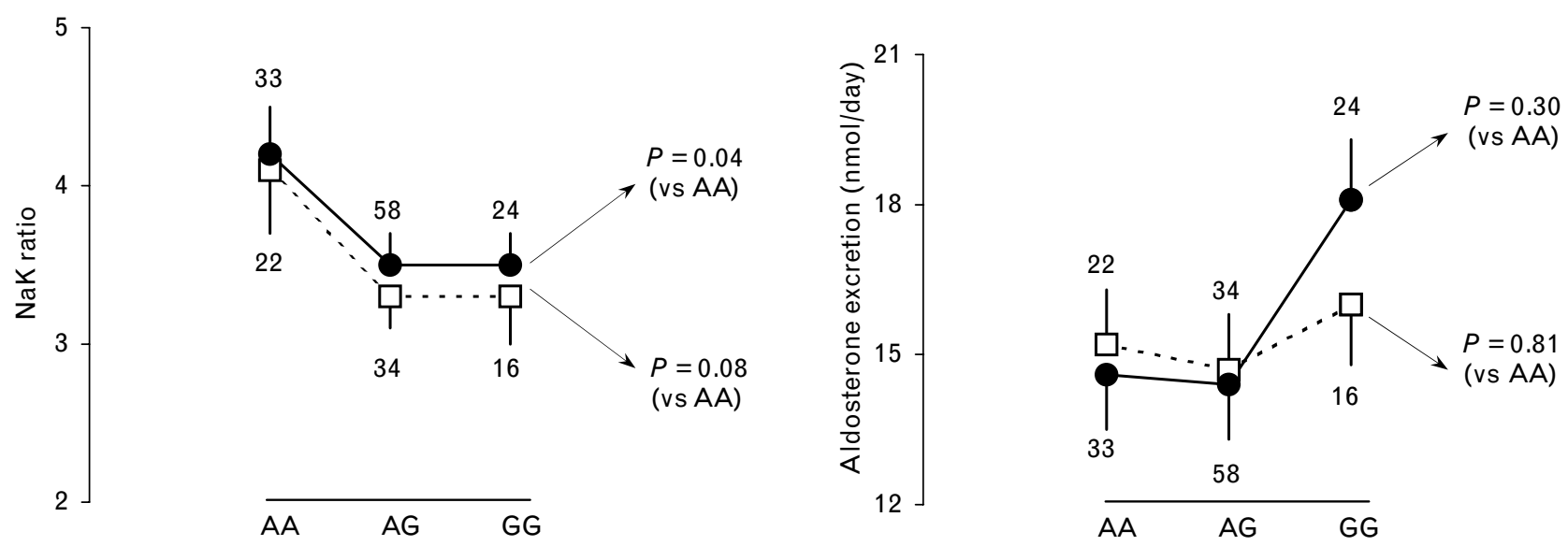

$\gamma$-Adducin genotype

$\gamma$-Adducin genotype

Peripheral and central pulse pressures and urinary $\mathrm{Na}^{+} / \mathrm{K}^{+}(\mathrm{NaK})$ ratio and aldosterone excretion by $\gamma$-adducin genotype and generation in carriers of the $\alpha$-adducin Trp allele. For adjustments of pulse pressures and urinary phenotypes, see Tables 3 and 4 , respectively. Vertical lines denote SEs. The number of subjects contributing to each mean is given.

Sensitivity analyses in founders and offspring separately, confirmed the associations of peripheral and central pulse pressures (Fig. 2) and the urinary $\mathrm{Na}^{+} / \mathrm{K}^{+}$ratio (Fig. 2) with the $\gamma$-adducin polymorphism in the presence of the mutated $\alpha$-adducin Trp allele. There was no significant interaction between $\alpha$ - and $\beta$-adducin in relation to any of the aforementioned phenotypes $(0.10 \leq P \leq 0.99)$. Furthermore, in all subjects combined, the results for pulse pressure remained consistent if we additionally adjusted for hypertension status, irrespective of whether we kept mean arterial pressure in the model.

\section{Family-based association study}

Abecasis' orthogonal model did not reveal population stratification in any country $(0.07 \leq P \leq 0.95)$. In all informative offspring, none of the aforementioned phenotypes was significantly associated with the transmission of the $\alpha$-adducin Trp allele $(P \geq 0.22)$, the $\beta$-adducin T allele $(P \geq 0.14)$ or the $\gamma$-adducin $\mathrm{G}$ allele $(P \geq 0.07)$.
However, in offspring carrying the mutated $\alpha$-adducin Trp allele, transmission of the $\gamma$-adducin $G$ allele was associated with significant increases in peripheral pulse pressure (Table 5) and systolic pressure measured at the

Table 5 Association between phenotypes and transmission of the $\gamma$-adducin $G$ allele to offspring carrying the $\alpha$-adducin Trp allele

\begin{tabular}{lccccc}
\hline & & \multicolumn{4}{c}{ Statistical parameters } \\
\cline { 3 - 6 } Phenotypes & Number of offspring & & & & \\
(informative/all) & $\beta$ & Units & $\chi^{2}$ & $P$ \\
\hline Pulse pressures & & & & & \\
$\quad \begin{array}{l}\text { Peripheral } \\
\quad \text { Central }\end{array}$ & $83 / 128$ & +4.6 & $\mathrm{mmHg}$ & 8.75 & 0.006 \\
& $83 / 128$ & +2.2 & $\mathrm{mmHg}$ & 2.70 & 0.10 \\
Urinary phenotypes & & & & & \\
$\quad \mathrm{Na}^{+} / \mathrm{K}^{+}$ratio & $75 / 115$ & -0.6 & units & 5.36 & 0.02 \\
$\quad$ Aldosterone excretion & $75 / 115$ & +9.6 & $\%$ change & 0.33 & 0.56
\end{tabular}

The orthogonal model accounted for between- and within-family components of phenotypic variability. The parameter estimate $(\beta)$ for the within-family variability component indicates the direction and size of the association when the $\gamma$-adducin $\mathrm{G}$ allele was transmitted. For adjustments of the pulse pressures and the urinary phenotypes, see Tables 3 and 4, respectively. 
level of the brachial artery (effect size $+5.0 \mathrm{mmHg}$; $\left.\chi^{2}=9.23 ; P=0.002\right)$ with a similar, but non-significant trend in central pulse pressure (Table 5). Furthermore, among carriers of the $\alpha$-adducin Trp allele, transmission of the $\gamma$-adducin $G$ allele was associated with a decrease in the urinary $\mathrm{Na}^{+} / \mathrm{K}^{+}$ratio (Table 5), while among GlyGly homozygotes $\mathrm{G}$ allele transmission was associated with a slight decrease in the aldosterone excretion (effect size $\left.-17.4 \% ; \chi^{2}=3.28 ; P=0.07\right)$.

\section{Discussion}

The key finding of our study was an epistatic interaction between the $\alpha$ - and $\gamma$-adducin genes, which in three European populations of Caucasian extraction impacted on pulse pressure and the relative concentrations of sodium and potassium in urine. Indeed, the $\gamma$-adducin $G$ allele was associated with higher peripheral and central pulse pressures and lower urinary $\mathrm{Na}^{+} / \mathrm{K}^{+}$ratio in $\alpha$ adducin Trp allele carriers, and with lower aldosterone excretion in $\alpha$-adducin GlyGly homozygotes. These findings emerged from a population-based association study. Sensitivity analyses in founders and offspring separately and a family-based QTDT approach subsequently confirmed these relations.

Adducin is a heterodimeric cytoskeleton protein and consists of subunits that share a similar structure, but are translated from three different genes [1]. ADD1 $(\alpha)$, $\operatorname{ADD} 2(\beta)$ and ADD3 $(\gamma)$ map to 4p16.3, 2p13-p14, and $10 \mathrm{q} 24.2-\mathrm{q} 24.3$, respectively $[1,19]$. The $\alpha-$ and $\gamma$-subunits are constituents of cell membranes at the actin-spectrin junctions across all tissues, whereas expression of the $\beta$-subunit occurs mainly in the brain and erythropoietic organs [1]. Thus, our present findings subscribe to what is known from a molecular point of view.

Previous studies in populations and patients demonstrated that the $\alpha$-adducin Gly460Trp polymorphism, alone or in combination with variation in the genes encoding $\beta$-adducin [8], angiotensin-converting enzyme or aldosterone synthase, influences the prevalence and incidence of hypertension [6], the serum creatinine concentration [7], proteinuria [7], intima-media thickness of the femoral artery [10], distensibility of the large arteries [11] and the risk of cardiovascular events [20]. On the other hand, other researchers [21-24], mostly in singlegene studies, failed to demonstrate an association between blood pressure analysed as a continuous or dichotomous trait and the $\alpha$-adducin polymorphism.

The mechanisms underlying our present observations, which link peripheral and central pulse pressures with changes in the urinary $\mathrm{Na}^{+} / \mathrm{K}^{+}$ratio and aldosterone excretion, remain to be elucidated. However, based on current knowledge, several pathophysiological pathways might be implicated. First, investigations in rats [2], in vitro transfection studies [3], dietary [25] and pharmacological [26] interventions in hypertensive patients, and epidemiological studies [6-8] revealed a coherent sequence of events leading from a point mutation in the $\alpha$-adducin subunit to a cellular dysfunction characterized by higher activity of the sodium pump [3], hence increased tubular sodium reabsorption in the kidney [27], and ultimately hypertension [6]. In keeping with this body of evidence, we found that the increase in pulse pressure was due to an elevation in systolic pressure without decrease in diastolic pressure. From a haemodynamic point of view, these findings suggested that, in addition to systolic blood pressure, also mean blood pressure was elevated, either due to an increase in stroke volume, peripheral resistance or both factors. Analysis of our data confirmed the elevation of mean blood pressure (data not shown) with the $\gamma$ adducin $G$ allele in $\alpha$-adducin Trp carriers.

Furthermore, it is conceivable that the constitutive activation of the sodium pump in $\alpha$-adducin $\operatorname{Trp}$ allele carriers not only occurs in renal tubular cells, but that it might also be present in vascular smooth muscle cells or adrenal glomerulosa cells. The carboxy-terminal region of the adducin subunits contains the binding site for calmodulin and is required for the interaction with spectrin and actin [1]. In vascular myocytes, enhanced $\mathrm{Na}^{+}, \mathrm{K}^{+}$-ATPase activity might reduce the sarcolemmal $\mathrm{Na}^{+} / \mathrm{Ca}^{2+}$ exchange and, through calcium-dependent pathways, modulate excitation-contraction coupling and the expression of growth-related genes [28]. A similar mechanism might also apply to adrenal glomerulosa cells. Indeed, potassium stimulates the secretion of aldosterone via depolarization of the cell membrane, which activates voltage-dependent calcium channels [29]. Via activation of the $\mathrm{Na}^{+}, \mathrm{K}^{+}$-ATPase activity, mutations in the adducin genes might influence the cytosolic calcium concentration in adrenal cells and interfere with the regulation of the aldosterone biosynthesis [30].

Dependent on the $\alpha$-adducin genotype, we noticed dissociation between the urinary $\mathrm{Na}^{+} / \mathrm{K}^{+}$ratio and the aldosterone excretion. Indeed, in $\alpha$-adducin GlyGly homozygotes, the urinary $\mathrm{Na}^{+} / \mathrm{K}^{+}$ratio was similar across the $\gamma$-adducin genotypes, whereas aldosterone excretion was $31 \%$ lower in GG than AA homozygotes. Conversely, with the mutated $\alpha$-adducin Trp allele in the background, the urinary $\mathrm{Na}^{+} / \mathrm{K}^{+}$ratio was $19 \%$ lower in $\gamma$ adducin $\mathrm{G}$ allele carriers than in AA homozygotes, with no significant differences in the aldosterone excretion. The observation, that in young as well as older rats $\gamma$ adducin is expressed in the adrenal gland at higher concentrations than in most other tissues, is likely to be relevant to our present findings [31]. In addition to the adrenal aldosterone biosynthesis, adducin might also affect other regulators and hormones underlying the urinary $\mathrm{Na}^{+} / \mathrm{K}^{+}$ratio. For instance, in renal tubular cells, the serine-threonine kinase WNK4 acts as a molecular switch of various ion transporters, which can vary the 
balance between $\mathrm{NaCl}$ reabsorption and $\mathrm{K}^{+}$secretion [32]. Although in the distal nephron the electrogenic epithelial sodium channel provides the driving force for $\mathrm{K}^{+}$secretion [33], changes in $\mathrm{Na}^{+}, \mathrm{K}^{+}$-ATPase activity due to mutations in adducin might also impact on transepithelial ion transport. Furthermore, we previously demonstrated that, in the population at large, the plasma concentration of endogenous ouabain, a steroid hormone released from the adrenal gland and possibly from the hypothalamus [34], increases with the number of mutated $\alpha$-adducin Trp alleles [35]. At very low concentrations within the nanomolar range, endogenous ouabain may enlarge the membrane pool of active sodium pumps [36] and activate mediators of cell growth [28,34]. To what extent the aforementioned pathways might increase pulse pressure, either via renally mediated effects on the circulating plasma volume and cardiac output or via structural or functional alterations in the vasculature, must be further clarified.

The present study has to be interpreted within the context of its limitations and strengths. We measured only one single nucleotide polymorphism per gene and we may therefore have underestimated the full functional impact of the adducin genes on pulse pressures. We did not measure the intermediate phenotypes, which might link pulse pressure with changes in sodium and potassium homeostasis, such as the plasma concentration of endogenous ouabain. Because of this, our pathophysiological interpretations should be considered as hypothesis-generating and should withstand the test of confirmatory evidence and experimental investigation. Peripheral and central pulse pressures are quantitative traits, which arise through complex interaction between multiple genes and environmental factors and are prone to measurement error. In the present study, only four experienced observers performed all measurements of central pulse pressure, with high intra-observer intrasession reproducibility. We derived the peripheral pulse pressure from five conventional blood pressure readings at the subjects' homes, for which a quality assurance and quality control programme was implemented across all EPOGH centres, with satisfactory results [37]. More importantly, the peripheral and central pulse pressures were measured on different occasions with different techniques, but nevertheless both phenotypes were consistently influenced by the polymorphisms in the $\alpha$ - and $\gamma$-adducin genes. There was also a high degree of internal consistency between the results of the population-based and family-based analyses, which started from divergent assumptions with implementation of different statistical algorithms, and between the findings within each country (data not shown) and in the whole study sample. The QTDT approach is not sensitive to population stratification or admixture. Our findings can also be readily generalized, because we recruited population samples randomly in three different European countries.
In conclusion, in carriers of the mutated $\alpha$-adducin Trp allele, peripheral and central pulse pressures increase with the $\gamma$-adducin $G$ allele. This epistatic interaction is physiologically consistent with the heterodimeric structure of the cytoskeleton protein adducin. The underlying molecular mechanisms remain to be elucidated, but might involve dysregulation of transmembranous active sodium transport $[3,4]$ at the renal, adrenal or systemic level.

\section{Acknowledgements}

Michael F. O'Rourke (Saint Vincent's Hospital, Darlinghurst, Sydney, Australia) helped with the interpretation of the SphygmoCor data. This study would not have been possible without the voluntary collaboration of the participants. The authors acknowledge the expert assistance of Rina Bollen, Sandra Covens, Lieve Gijsbers, MarieJeanne Jehoul, Sylvia Van Hulle, and Renilde Wolfs (Study Coordinating Centre, University of Leuven, Leuven, Belgium).

\section{References}

1 Matsuoka Y, Li X, Bennett V. Adducin: structure, function, and regulation. Cell Mol Life Sci 2000; 57:884-895.

2 Bianchi G, Tripodi G, Casari G, Salardi S, Barber BR, Garcia R, et al. Two point mutations within the adducin genes are involved in blood pressure variation. Proc Natl Acad Sci USA 1994; 91:3999-4003.

3 Tripodi G, Valtorta F, Torielli L, Chieregatti E, Salardi S, Trusolino L, et al. Hypertension-associated point mutations in the adducin $\alpha$ and $\beta$ subunits affect actin cytoskeleton and ion transport. J Clin Invest 1996; 97:28152822

4 FerrandiM,SalardiS, TripodiG, BarrasiP, RiveraR, ManuntaP, etal. Evidence for an interaction between adducin and $\mathrm{Na}^{+}-\mathrm{K}^{+}$-ATPase: relation to genetic hypertension. Am J Physiol 1999; 277:H1338-H1349.

5 Salvati P, Pinciroli GP, Bianchi G. Renal function of isolated perfused kidneys from hypertensive (MHS) and normotensive (MNS) rats of the Milan strain at different ages. J Hypertens Supp/ 1984; 2:S351-S353.

6 Staessen JA, Wang JG, Brand E, Barlassina C, Birkenhager WH, Herrmann SM, et al. Effects of three candidate genes on prevalence and incidence of hypertension in a Caucasian population. $J$ Hypertens 2001 ; 19:1349-1358.

7 Wang JG, Staessen JA, Tizzoni L, Brand E, Birkenhager WH, Fagard R, et al. Renal function in relation to three candidate genes. Am J Kidney Dis 2001; 38:1158-1168.

8 Wang JG, Staessen JA, Barlassina C, Fagard R, Kuznetsova T, StruijkerBoudier HA, et al. Association between hypertension and variation in the $\alpha$-and $\beta$-adducin genes in a white population. Kidney Int 2002; 62:21522159.

9 TikhonoffV, KuznetsovaT,StolarzK, BianchiG, CasigliaE, Kawecka-JaszczK, et al. $\beta$-Adducin polymorphisms, blood pressure, and sodium excretion in three European populations. Am J Hypertens 2003; 16:840-846.

10 Balkestein EJ, Wang JG, Struijker-Boudier HA, Barlassina C, Bianchi G, Birkenhager $\mathrm{WH}$, et al. Carotid and femoral intima-media thickness in relation to three candidate genes in a Caucasian population. $J$ Hypertens 2002; 20:1551-1561.

11 Balkestein EJ, Staessen JA, Wang JG, van der Heijden-Spek JJ, Van Bortel LM, Barlassina C, et al. Carotid and femoral artery stiffness in relation to three candidate genes in a white population. Hypertension 2001;38:1190-1197.

12 O'Rourke MF, Staessen JA, Vlachopoulos C, Duprez D, Plante GE. Clinical applications of arterial stiffness; definitions and reference values. $A m \mathrm{~J}$ Hypertens 2002; 15:426-444.

1341 st World Medical Assembly. Declaration of Helsinki: recommendations guiding physicians in biomedical research involving human subjects. Bull Pan Am Health Organ 1999; 24:606-609.

14 Chen $\mathrm{CH}$, Nevo E, Fetics B, Pak PH, Yin FC, Maughan WL, et al. Estimation of central aortic pressure waveform by mathematical transformation of radial tonometry pressure. Validation of generalized transfer function. Circulation 1997; 95:1827-1836.

15 Luft FC, Fineberg NS, Sloan RS. Estimating dietary sodium intake in individuals receiving a randomly fluctuating intake. Hypertension 1982; 4:805-808. 
16 Staessen JA, Bulpitt CJ, Fagard R, Joossens JV, Lijnen P, Amery A. Salt intake and blood pressure in the general population: a controlled intervention trial in two towns. J Hypertens 1988; 6:965-973.

17 The SAS Institute. The GENMOD Procedure. SAS Online Doc Version 7.1. Cary, North Carolina: SAS/STAT; 2000, pp. 1311-1411.

18 Abecasis GR, Cordon LR, Cookson WO. A general test of association for quantitative traits in nuclear families. Am J Hum Genet 2000; 66:279292.

19 Citterio L, Azzani T, Duga S, Bianchi G. Genomic organization of human $\gamma$-adducin gene. Biochem Biophys Res Commun 2003; 266:110-114.

20 Psaty BM, Smith NL, Heckbert SR, Vos HL, Lemaitre RN, Reiner AP, et al. Diuretic therapy, the $\alpha$-adducin gene variant, and the risk of myocardial infarction or stroke in persons with treated hypertension. JAMA 2002; 287:1680-1689.

21 Turner ST, Chapman AB, Schwarzt GL, Boerwinkle E. Effects of endothelial nitric oxide synthase, alpha-adducin, and other candidate gene polymorphisms on blood pressure response to hydrochlorothiazide. Am J Hypertens 2003; 16:834-839.

22 Castejon AM, Alfieri AB, Hoffmann IS, Rathinavelu A, Cubeddu LX. Alphaadducin polymorphism, salt sensitivity, nitric oxide excretion, and cardiovascular risk factor in normotensive Hispanics. Am J Hypertens 2003; 16:1018-1024.

23 Shioji K, Kokubo Y, Mannami T, Inamoto N, Morisaki $\mathrm{H}$, Mino $\mathrm{Y}$, et al Association between hypertension and the alpha-adducin, beta1adrenoreceptor, and G-protein beta3 subunit genes in the Japanese population; the Suita study. Hypertens Res 2004; 27:31-37.

24 Conway BR, Martin R, McKnight AJ, Savage DA, Brady HR, Maxwell AP. Role of alpha-adducin DNA polymorphisms in the genetic predisposition to diabetic nephropathy. Nephrol Dial Transplant 2004; 19:2019-2024.

25 Barlassina C, Schork NJ, Manunta P, Citterio G, Sciarrone M, Lanella G et al. Synergistic effect of $\alpha$-adducin and ACE genes causes blood pressure changes with body sodium and volume expansion. Kidney Int 2000; 57:1083-1090.

26 Sciarrone MT, Stella P, Barlassina C, Manunta P, Lanzani C, Bianchi G et al. ACE and $\alpha$-adducin polymorphism as markers of individual response to diuretic therapy. Hypertension 2003; 41:398-403.

27 Manunta P, Burnier M, D'Amico M, Buzzi L, Millard M, Barlassina C, et al Adducin polymorphism affects renal proximal tubule reabsorption in hypertension. Hypertension 1999; 33:694-697.

28 Orlov SN, Adragna NC, Adarichev VA, Hamet P. Genetic and biochemical determinants of abnormal monovalent ion transport in primary hypertension. Am J Physiol 1999; 276:C511-C536.

29 Quinn SJ, Williams GH. Regulation of aldosterone secretion. Annu Rev Physiol 1988; 50:409-429.

30 Kramer RE, Gallant S, Brownie AC. Action of angiotensin II on aldosterone biosynthesis in the rat adrenal cortex. J Biol Chem 1980; 255:34423447.

31 Tripodi G, Modica R, Reina C, Bianchi G. Tissue-specific modulation of $\beta$-adducin transcripts in Milan hypertensive rats. Biochem Biophys Res Commun 2003; 303:230-237.

32 Kahle KT, Wilson FH, Leng $\mathrm{Q}$, Lalioti MD, O'Connell AD, Dong K, et al. WNK4 regulates the balance between renal $\mathrm{NaCl}$ reabsorption and $\mathrm{K}^{+}$ secretion. Nat Genet 2003; 33:372-376.

33 Bindels RJM. A molecular switch controlling renal sodium and potassium excretion. Nat Genet 2003; 33:302-303.

34 Schoner W. Endogenous cardiac glycosides, a new class of steroid hormone. Eur J Biochem 2002; 269:2440-2448.

35 Wang JG, Staessen JA, Messaggio E, Nawrot T, Fagard R, Hamlyn JM, et al. Salt, endogenous ouabain and blood pressure interactions in the general population. J Hypertens 2003; 21:1475-1481.

36 Ferrari $\mathrm{P}$, Ferrandi M, Torielli L, Barassi P, Tripodi G, Minotti E, et al. Antihypertensive compounds that modulate the Na-K pump. Ann NY Acad Sci 2003; 986:694-701.

37 Kuznetsova T, Staessen JA, Kawecka-Jaszcz K, Babeanu S, Casiglia E, Filipovský J, et al. Quality control of the blood pressure phenotype in the European Project on Genes in Hypertension. Blood Press Monit 2002 7:215-224.

\section{Appendix \\ EPOGH centres}

Belgium (Hechtel-Eksel)

E. Balkestein, R. Bollen, H. Celis, S. Covens, E. Den Hond, L. De Pauw, P. Drent, D. Emelianov, R. Fagard, L. Gijsbers, A. Hermans, T. Nawrot, L. Thijs, Y.Toremans,
J.A. Staessen, S. Van Hulle, J.G. Wang, R. Wolfs and P.E. Zabekakis.

\section{Bulgaria (Sofia)}

C. Nachev, A. Postadjian, E. Prokopova, E. Shipkovenska and K. Vitljanova.

\section{Czech Republic (Pilzen)}

J. Filipovský, J. Kucerová, V. Svobodová and M. Tichá.

\section{Czech Republic (Prague)}

O. Beran, L. Golán, T. Grus, Z. Marecková and J. Peleška.

\section{Italy (Padova)}

E. Casiglia, A. Pizzioli and V. Tikhonoff.

\section{Poland (Cracow)}

A. Adamkiewicz-Piejko, M. Cwynar, J. Gạsowski, T. Grodzicki, K. Kawecka-Jaszcz, W. Lubaszewski, A. Olszanecka, K. Stolarz, B. Wizner, W. Wojciechowska and J. Życzkowska.

\section{Romania (Bucharest)}

S. Babeanu, D. Jianu, C. Sandu, D. State and M. Udrea.

\section{Russian Federation (Novosibirsk)}

T. Kuznetsova, S. Malyutina, Y. Nikitin, E. Pello, M. Ryabikov and M. Voevoda.

\section{Coordination and committees Project coordinator}

J.A. Staessen.

\section{Scientific coordinator}

K. Kawecka-Jaszcz.

\section{Steering committee}

S. Babeanu (Romania), E. Casiglia (Italy), J. Filipovský (Czech Republic), K. Kawecka-Jaszcz (Poland), C. Nachev (Bulgaria), Y. Nikitin (Russian Federation), J. Peleška (Czech Republic) and J.A. Staessen (Belgium).

\section{Data management committee}

T. Kuznetsova, J.A. Staessen, K. Stolarz, V. Tikhonoff and J.G. Wang.

\section{Publication committee}

E. Casiglia, K. Kawecka-Jaszcz and Y. Nikitin.

\section{Advisory committee on molecular biology}

G. Bianchi (Milan), E. Brand (Berlin) and H.A. StruijkerBoudier (Maastricht).

\section{EPOGH-EurNetGen liaison}

A. Dominiczak (Glasgow) and J.A. Staessen (Leuven). 


\section{Studies on genes and hypertension: a daunting task Juan M. Saavedra}

\author{
Journal of Hypertension 2005, 23:929-932 \\ Section on Pharmacology, Division of Intramural Research Programs, National \\ Institute of Mental Health, National Institutes of Health, Department of Health and \\ Human Services, Bethesda, Maryland, USA. \\ Correspondence and requests for reprints to Juan M. Saavedra M.D., Section on \\ Pharmacology, DIRP, NIMH, NIH, DHHS, 10 Center Drive, Building 10, Room \\ 2D-57, Bethesda, MD 20892, USA. \\ Tel: +1 301496 0160; fax: +1 301402 0337; e-mail: saavedrj@mail.nih.gov
}

\section{See original article on page 961}

\section{Introduction}

Genetic elements contribute to $30-50 \%$ of the blood pressure variability in human essential hypertension [1]. Studies aiming to identify contributing genes will allow us to recognize those vulnerable individuals, and to classify patients in subgroups with definite genetic and pathogenic mechanisms, to achieve better prevention and therapeutics. Genes involved in renal sodium handling are of particular interest because alterations in renal function and sodium reabsorption are associated with long-term increases in blood pressure. Good examples are the genes encoding for adducin $\alpha, \beta$ and $\gamma$ subunits. Adducin is ubiquitously expressed and is involved in multiple functions, including cell motility and synaptic transmission $[2,3]$. The role of adducin includes stimulation of $\mathrm{Na}^{+}-\mathrm{K}^{+}$-ATPase activity, the key enzyme for tubular $\mathrm{Na}$ transport [4].

The hypothesis that adducin is important in hypertension originated with the development of an experimental genetic model, the hypertensive Milan rat strain [5]. The proposed molecular mechanism in the Milan rat strain involved adducin polymorphism, leading to increased $\mathrm{Na}^{+}-\mathrm{K}^{+}$ATP-ase activity and enhanced renal tubular sodium reabsorption, facilitating the development of hypertension. An $\alpha$-adducin allele was shown to co-segregate with blood pressure in the Milan rat strain [6].

Initial clinical studies associated the $\alpha$-adducin polymorphism (consisting of tryptophan instead of glycine at amino acid number 460, Gly460Trp) with hypertension [7]. This was followed by a report of selective association with hypertension in Caucasian populations characterized by low plasma renin activity [5]. Hypertensives with at least one copy of the Gly460Trp allele and low plasma renin activity showed enhanced proximal tubular reabsorption and a more pronounced fall in blood pressure after chronic diuretic treatment or acute sodium depletion [8-10]. This suggested a genetic basis for selective anti-hypertensive therapy in groups of patients characterized by specific mechanisms, such as those involved in the renal handling of sodium.

In the Milan rat strain, the $\gamma$-adducin polymorphism was later associated with hypertension through non-additive gene-gene (epistatic) interaction with the $\alpha$-subunit [5]. Two recent reports in the Journal of Hypertension $[11,12]$ provide clinical correlates for the $\alpha$ - and $\gamma$-adducin epistatic interaction. In a population of never-treated hypertensive subjects, Gly460Trp polymorphism was associated with very small increases in blood pressure and lower plasma renin activity and ouabain, supporting the hypothesis that the $\alpha$-adducin allele stimulates $\mathrm{Na}^{+}$ reabsorption, and of altered renal sodium retention in hypertension. In turn, the Ala386Gly $\gamma$-adducin allele was associated with higher blood pressures in the Gly460Trp population [11]. In a population-based study of three different European groups, epistatic interactions between $\alpha$ - and $\gamma$-adducin were associated with alterations in peripheral and central pulse pressure, and index of vascular stiffness as a consequence of chronically increased blood pressure [12]. In carriers of the Gly460Trp polymorphism, the peripheral and central pulse pressure increased with the presence of the $\gamma$-adducin Ala386Gly allele. In addition, $\alpha$-adducin GlyGly homozygoty was associated with a lower urinary $\mathrm{Na}^{+} / \mathrm{K}^{+}$ratio among $\alpha$-adducin $\operatorname{Trp}$ allele carriers and with higher urinary aldosterone excretion among $\alpha$-adducin GlyGly homozygotes. The proposed association between adducin alleles, low renin hypertension, renal sodium reabsorption and response to diuretics, now confirmed by family studies, appears of to be interest because of its promise of identifying a subgroup of essential hypertensive patients with specific genetic attributes and increased sensitivity to a particular class of antihypertensive medications.

The original adducin hypothesis, as formulated 10 years ago, generated numerous replication and expansion studies. Unfortunately, as is the case with most if not all initial studies on the genetics of hypertension, the results of replication studies and a further analysis of the genetic and environmental context are not encouraging.

Frequency of the $\alpha$-adducin allele in human populations The prevalence of adducin variants differs among populations, and is much higher in oriental (Chinese and Japanese) and lower in black South Africans than in 
Caucasians [5,8,13-15]. More importantly, the frequency of the Gly460Trp allele in a Scandinavian population was even lower in hypertensives than in normotensive controls [16].

\section{Association of $\alpha$-adducin polymorphism and hypertension}

The initial positive studies reported an association of adducin polymorphism and hypertension in an Italian population [7]. Follow-up studies of different populations did not replicate the initial report, with the exception of one study of a Black population born and living in Africa [14]. No association between the Gly460Trp allele and hypertension occurred in Asian (Chinese or Japanese) [15,17], Scottish [18], Scandinavian [16] or American populations [19,20]. The conclusion, from a series of studies supported by the Family Blood Pressure Program, was that the $\alpha$-adducin gene did not have a major impact on the occurrence of hypertension [21]. Yet another report found an association in Whites, but not in Blacks, where the adducin polymorphism appeared to be protective against hypertension [22].

\section{Association of $\alpha$-adducin polymorphism with low renin hypertension and salt sensitivity}

Attempts to link the Gly460Trp in specific subgroups of patients have also been inconsistent. The report of an association of Gly460Trp polymorphism with salt sensitivity and lower renin activity $[8,23]$ was confirmed in Japanese populations [13,24-26] but the findings did not hold for Scottish [27] or Hispanic [28] populations. In the Hispanic population, the Gly460Trp allele associated, in a subset of hypertensives with salt sensitivity, only with greater salt-dependent modulation of NO excretion [28].

\section{Context-dependent effects}

Age and gender condition the adducin-hypertension association. The association of Gly460Trp polymorphism with low renin hypertension holds only for young subjects [24]. A report of a large cohort of a Japanese population concluded that the Gly460Trp polymorphism associates with hypertension only in females [29].

\section{Pharmacogenetic studies and association with end organ damage}

The initial pharmacogenetic studies that focused on blood pressure responses to thiazide diuretics have not been confirmed [30]. In a population-based, case-control study of a single nucleotide polymorphism in survivors of myocardial infarct or stroke, diuretics were associated with a lower risk of myocardial infarction and stroke but not with mean levels of blood pressure [31]. This suggests that in salt-sensitive hypertensives, diuretic therapy decreases the incidence of cardiovascular events through mechanisms other than the direct lowering of blood pressure, and that blood pressure differences may not predict the effects of drugs on cardiovascular end points. In an Irish population, the Gly460Trp variant did not associate with nephropathy or hypertension in type 1 diabetic patients [32]. Moreover, the $\alpha$-adducin polymorphism has been recently associated with a significant protective effect on myocardial infarct [33].

In conclusion, follow-up studies have not replicated or confirmed the initial hypothesis of a major role of adducin polymorphisms in essential hypertension, and the role of adducin genes in hypertension remains elusive. Failure to confirm the role of candidate genes is not restricted to adducin, and has been recently reported for the ACEI/D and the AGT M235T polymorphisms [34,35]. Problems with studies of genetic associations in complex heterogeneous disorders are not limited to studies on essential hypertension. The frustration was so high that the question was raised as to whether or not association studies should be published at all in high-impact Journals [36]. Experts in the field are reaching an emerging consensus on these problems, and on the solutions to avoid confusion and further disappointments. Below, some of the problems and the proposed solutions are identified.

\section{The problems \\ Complexity of the disease: influence of the environment and genetic context}

A complex combination of processes, metabolic systems and intermediate traits, involving a redundancy of balancing pressor and depressor roles, controls blood pressure. Hypertension is probably a polygenic disease with complex interactions of networked genes with environmental stimuli, and a few alleles in a handful of genes are not likely to explain increased blood pressure. The pathogenic mechanisms are very complex and include elements of the metabolic syndrome, obesity and cardiovascular risk factors. Because of this, the influence of any genetic factor such as adducin is likely to be small, and dependent on the genetic context and environmental factors. This is why apparently there is a decreased support for genetic linkage with increasing sample size.

\section{Population heterogeneity}

The prevalence, age of onset, severity and complications of hypertension are not similar among ethnic groups, indicating the contribution of different sets of genes. The effect of only one gene is likely to be small and inconsistent across different genetic and environmental backgrounds. A genetic variation may only have a significant effect in particular subgroups of the population defined by some other genetic or environmental context, with minimal or no association in other subgroups of the population.

The expectations that initial findings will hold in different populations, indicating a universal association between the gene and the phenotype, usually fail. For the reasons stated above, differences among populations are not surprising but rather expected [37]. 


\section{Complexity of pharmacogenetics}

Does the adducin variant alone identify a subset of hypertensive patients who are particularly likely to benefit from diuretic therapy? The results of follow-up studies have also been discouraging. Hypertension is characterized by large inter-patient variability in response to drugs, and there are multiple genetic variants influencing response to anti-hypertensive therapy, including inter-individual variability in rates of drug metabolism. For example, numerous polymorphisms related to gut, liver, blood and renal function have been implicated in the response to diuretics, indicating the complex interplay of many pathways [38].

\section{The solutions}

\section{Address the aetiological heterogeneity of essential hypertension}

A single locus model is not adequate for analysis of a complex phenotype.

When there is aetiological heterogeneity, analysis of subgroups can enhance gene finding or hidden genetic heterogeneity because different hypertension genes operate in different subsets of families. Gene-gene, gene-genetic background and gene-environment interactions may be at play.

In addition, adequate genetic analysis and phenotype definition will not be possible until basic mechanisms and interactions are understood. Future studies should analyse the contribution of adducin not only on the pathophysiology of sodium handling, but also focus on the functional characteristics related to sodium transport, such as sodium pump activity and blood pressure responses to changes in sodium balance. Many cells express adducin subunits and this protein could play additional roles in multiple functions, such as the regulation of neurotransmitter activity [39].

\section{Improve study design}

There is an urgent need for a limited and generally accepted set of methods that permit appropriate assessment and comparison of individual results. To validate a hypothesis, further tests are necessary and require independent replication. Because negative evidence in replication studies is expected from statistical theory [37], the size of the sample and the power of the statistical tests utilized become crucial for analysis and selection of competing hypothesis.

Replication should reproduce the original definition of cases and controls, and include a population of similar extraction and similar ethnic background, using the same inclusion and exclusion criteria. The phenotype should be carefully defined, in terms of age of onset and present age, gender, disease severity and body size.
Environmental exposure and lifestyle must be similar to that of the original report [37].

Mutual influences among the metabolic effects of genetic variations are the norm rather than the exception, and there is a need to study gene-gene interactions and multiple polymorphisms within large epidemiological samples. Will the study of haplotypes (chromosomal segments preserved intact over many generations that may account for the vast majority of diversity in populations) be powerful predictors of disease [33]?

Subjects on antihypertensive treatments should be included because familial components of blood pressure variance are important, and this information is lost, reducing the evidence of linkage, if treated patients are excluded $[40,41]$. To deal with treatment effects we need special analytical methods [41].

Association studies of high quality should include large sample sizes and high statistical power, report associations that make biological sense containing an initial study as well as an independent replication, and systematically investigate the interaction among genes and the environment [42].

Although associations in population-based studies are useful, family-based analysis is more powerful for detecting linkage and/or linkage disequilibrium [35,43].

\section{Focus on pharmacogenetics of selected populations}

Will the patient's genetic profile be important in the future to decide how to treat hypertension? Work in pharmacogenetics promises to improve the safety and efficacy profile of commonly used medications and help individualize treatment, selecting drug therapies that maximize effectiveness and safety. Many questions remain to be answered before this fantasy becomes reality. Drug treatment based on genomic traits must be scrutinized rigorously because therapeutic recommendations may be valid for selected populations only [34].

\section{Develop a multidisciplinary approach}

Boerwinkle [21] has called for a collaborative multidisciplinary approach, with the combination of information obtained from similar studies, the sharing and combining of results before publication and the combining of data resources being necessary. Such an approach should also eliminate any positive publication bias and the tendency to over interpret marginal results.

\section{Conclusions}

It is discouraging that in spite of intense efforts (9113 PubMed-listed publications for 'human hypertension/ genetics'; 131 publications for 'human hypertension/ genetics/adducin') the field has not advanced beyond initial hopes that have been crushed by disappointments. 
It appears that increased funding and further molecular and statistical sophistication will not be sufficient to overcome the obstacles, and may very well add to the confusion. On the other hand, we cannot abandon genetic studies on hypertension and other complicated diseases. Recognition of the complexity of hypertension and the difficulties ahead, improved study design, data sharing and collaborative studies, coupled with stringent criteria for acceptance in high impact Journals, should slowly advance our understanding of a disease of such immense importance for clinical practice and public health.

\section{References}

1 Garcia EA, Newhouse S, Caulfield MJ, Munroe PB. Genes and hypertension. Curr Pharmaceut Design 2003; 9:1679-1689.

2 Matsuoka Y, Li X, Bennett V. Adducin: structure, function and regulation. Cell Mol Life Sci 2000; 57:884-895.

3 Ferrandi M, Bianchi G. Genetic mechanisms underlying the regulation of urinary sodium excretion and arterial blood pressure: the role of adducin Acta Physiol Scand 2000; 168:187-193.

4 Ferrandi M, Salardi S, Tripodi G, Barassi P, Rivera R, Manunta P, et al. Evidence for an interaction between adducin and $\mathrm{Na}^{+}-\mathrm{K}^{+}$-ATPase: relation to genetic hypertension. Am J Physiol 1999; 277:H1338H1349.

5 Bianchi G, Tripodi G. Genetics of hypertension: the adducin paradigm. Ann NY Acad Sci 2003; 986:660-668.

6 Bianchi G, Tripodi G, Casari G, Salardi S, Barber BR, Garcia R, et al. Two point mutations within the adducin genes are involved in blood pressure variation. Proc Natl Acad Sci USA 1994; 91:3999-4003.

7 Casari G, Barlassina C, Cusi D, Zagato L, Muirhead R, Righetti M, et al. Association of the $\alpha$-adducin locus with essential hypertension. Hypertension 1995; 25:320-326.

8 Cusi D, Barlassina C, Azzani T, Casari G, Citterio L, Devoto M, et al. Polymorphisms of alpha-adducin and salt sensitivity in patients with essential hypertension. Lancet 1997; 349:1353-1357.

9 Sciarrone MT, Stella P, Barlassina C, Manunta P, Lanzani C Bianchi G, Cusi D. ACE and $\alpha$-adducin polymorphism as markers of individual response to diuretic therapy. Hypertension 2003; 41:398403.

10 Manunta P, Burnier M, D'Amico M, Buzzi L, Maillard M, Barlassina C, et al. Adducin polymorphism affects renal proximal tubule reabsorption in hypertension. Hypertension 1997; 33:886-896.

11 Lanzani C, Citterio L, Jankaricova M, Sciarrone MT, Barlassina C, Fattori S et al. Role of the adducin family genes in human essential hypertension. $J$ Hypertens 2005; 23:543-549.

12 Cwynar M, Staessen JA, Tichá M, Nawrot T, Citterio L, Kuznetsova T, et al. Epistatic interaction between $\alpha$ - and $\beta$-adducin influences peripheral and central pulse pressures in White Europeans. J Hypertens 2005; 23: 961-969.

13 Iwai N, Tamaki S, Nakamura Y, Kinoshita M. Polymorphism of $\alpha$-adducin and hypertension. The Lancet 1997; 350:369.

14 Barlassina C, Norton GR, Samani NJ, Woodwiss AJ, Candy GC, Radevsk I, et al. $\alpha$-adducin polymorphism in hypertensives of South African ancestry. Am J Hypertens 2000; 13:719-723.

$15 \mathrm{He}$ X, Zhu DL, Chu SL, Jin L, Xiong MM, Wang GL, et al. Alpha-adducin gene and essential hypertension in China. Clin Exp Hypertens 2001; 23:579-589.

16 Melander O, Bengtsson K, Orho-Melander M, Lindblad U, Forsblom C Rastam L, et al. Role of the Gly460Trp polymorphism of the alpha-adducin gene in primary hypertension in Scandinavians. J Hum Hypertens 2000; 14:43-46.

17 Ranade K, Hsuing AC, Wu K-D, Chang M-S, Chen Y-T, Hebert J, et al. Lack of evidence for an association between $\alpha$-adducin and blood pressure regulation in Asian populations. Am J Hypertens 2000; 13:704709.

18 Clark CJ, Davies E, Anderson NH, Farmer R, Friel EC, Fraser R, Connell JM. Alpha-adducin and angiotensin l-converting enzyme polymorphisms in essential hypertension. Hypertension 2000; 36: 990-994.

19 Schork NJ, Chakravarti A, Thiel B, Fornage M, Jacob HJ, Cai R, et al. Lack of association between a biallelic polymorphism in the adducin gene and blood pressure in whites and African Americans. Am J Hypertens 2000; 13:693-698.
20 Bray MS, Li L, Turner ST, Kardia SLR, Boerwinkle E. Association and linkage analysis of the $\alpha$-adducin gene and blood pressure. Am J Hypertens 2000; 13:699-703.

21 Boerwinkle $\mathrm{E}$. All for one and one for all: introduction to a coordinated analysis of the Gly 460-Trp $\alpha$-adducin polymorphism. Am J Hypertens 2000; 13:734-735.

22 Province MA, Arnett DK, Hunt SC, Leiendecker-Foster C, Eckfeldt JH Oberman A, et al. Association between the $\alpha$-adducin gene and hypertension in the HyperGEN Study. Am J Hypertens 2000; 13:710718.

23 Castellano M, Barlassina C, Muiesan ML, Beschi M, Cinelli A, Rossi F, et al. Alpha-adducin gene-polymorphism and cardiovascular phenotypes in a general population. J Hypertens 1997; 15:1707-1710.

24 Sugimoto K, Hozawa A, Katsuya T, Matsubara M, Ohkubo T, Tsuji I, et al. Alpha-adducin Gly460Trp polymorphism is associated with low renin hypertension in younger subjects in the Ohasama study. $J$ Hypertens 2002; 20:1779-1784.

25 Katsuya T, Ishikawa K, Sugimoto K, Rakugi H, Ogihara T. Salt sensitivity of Japanese from the viewpoint of gene polymorphism. Hypertens Res 2003; 26:521-525.

26 Grant FD, Romero JR, Jeunemaitre X, Hunt SC, Hopkins PN, Hollenberg $\mathrm{NH}$, Williams $\mathrm{GH}$. Low-renin hypertension, altered sodium homeostasis, and an alpha-adducin polymorphism. Hypertension 2002; 39:191-196.

27 Kamitani A, Wong ZYH, Fraser R, Davies DL, Connor JM, Foy CJW, et al. Human $\alpha$-adducin gene, blood pressure, and sodium metabolism. Hypertension 1998; 32:138-143.

28 Castejon AM, Alfieri AB, Hoffmann IS, Rathinavelu A, Cubeddu LX. Alphaadducin polymorphism, salt sensitivity, nitric oxide excretion, and cardiovascular risk factors in normotensive Hispanics. Am J Hypertens 2003; 16:1018-1024.

29 Shioji K, Kokubo Y, Mannami T, Inamoto N, Morisaki H, Mino Y, et al. Association between hypertension and the alpha-adducin, beta1adrenoreceptor, and G-protein beta3 subunit genes in the Japanese population; the Suita study. Hypertens Res 2004; 27:31-37.

30 Turner ST, Chapman AB, Schwartz GL, Boerwinkle E. Effects of endothelial nitric oxide synthase, alpha-adducin, and other candidate gene polymorphisms on blood pressure response to hydrochlorothiazide. $\mathrm{Am} \mathrm{J}$ Hypertens 2003; 16:834-839.

31 Psaty BM, Smith NL, Heckbert SR, Vos HL, Lemaitre RN, Reiner AP, et al. Diuretic therapy, the alpha-adducin gene variant, and the risk of myocardial infarction or stroke in persons with treated hypertension. JAMA 2002; 287:1680-1689.

32 Conway BR, Martin R, McKnight AJ, Savage DA, Brady HR, Maxwell AP. Role of alpha-adducin DNA polymorphisms in the genetic predisposition to diabetic nephropathy. Nephrol Dial Transplant 2004; 19:2019-2024.

33 Tobin MD, Braund PS, Burton PR, Thompson JR, Steeds R, Channer K, et al. Genotypes and haplotypes predisposing to myocardial infarction: a multilocus case-control study. Eur Heart J 2004; 25:459-467.

34 Mondry A, Loh M, Liu P, Zhu A-L, Nagel M. Polymorphisms of the insertion/ deletion ACE and M235 AGT genes and hypertension: surprising new findings and meta-analysis of data. BMC Nephrol 2005; 6:1-11.

35 Luft FC. Geneticism of essential hypertension. Hypertension 2004; 43:1-5.

36 Anonymous. Freely associating. Nature Genet 1999; 22:1-2.

37 Lalouel J-M, Rohrwasser A. Power and replication in case-control studies. Am J Hypertens 2002; 15:201-205.

38 Vormfelde SV, Burckhardt G, Zirk A, Wojnowski L, Brockmöller J. Pharmacogenomics of diuretic drugs: data on rare monogenic disorders and on polymorphisms and requirements for further research. Pharmacogenomics 2003; 4:701-734.

39 Yang H, Francis SC, Sellers K, DeBarros M, Sun C, Sumners C, et al. Hypertension-linked decrease in the expression of brain $\gamma$-adducin. Circ Res 2002; 91:633-639.

40 Palmer LJ. Loosening the cuff. Important new advances in modeling antihypertensive treatment effects in genetic studies of hypertension. Hypertension 2003; 41:197-198.

41 Cui JS, Hopper JL, Harrap SB. Antihypertensive treatments obscure familial contributions to blood pressure variation. Hypertension 2003; 41:207-210.

42 Kardia SLR. Context-dependent genetic effects in hypertension. Curr Hypertens Reports 2000; 2:32-38.

43 Terwilliger JD, Haghighi F, Hiekkalinna TS, Göring HHH. A bias-ed assessment of the use of SNPs in human complex traits. Curr Opin Genet Dev 2002; 12:726-734. 